\title{
Pengaruh Relaksasi Otot Progresif terhadap Penurunan Dismenore pada Mahasiswi A 2012 Fakultas Keperawatan Unand
}

\author{
Israd Akbar ${ }^{b}$, Dewi Eka Putria ${ }^{a}$, Esi Afriyanti ${ }^{a}$ \\ ${ }^{a}$ Fakultas Keperawatan Universitas Andalas \\ ${ }^{b}$ Badan Penyelenggara Jaminan Sosial (BPJS) Kesehatan \\ Email: israd_akbar@yahoo.com
}

\begin{abstract}
Dysmenorrhea is menstrual pain that is felt when, mainly in the lower abdomen to the waist and thighs spread that feels like cramping. The pain is subjective. In the severe circumstances can be accompanied by nausea and vomiting. 60-70\% of patients with dysmenorrhea are younger women, resulting in a sense of discomfort and disruption have an impact on daily activities, academic and social. One of the nonpharmacological therapies that can be used to reduce dysmenorrhoea is progressive muscle relaxation. This study aims to determine whether the effect of progressive muscle relaxation in the pain management of dysmenorrhoea. Subject is a student at A 2012 study in the Faculty of Nursing Andalas. This research uses a quasi-experimental approach with no control group with one group pretest-posttest. Sampling using sampling with 37 people. Data analysis using the Wilcoxon. The research proves there is significant before and after progressive muscle relaxation to pain dysmenorrhoea on student A 2012 Faculty of Nursing in Andalas University with $p=0.000$ ( $p<0,05$ ). This shows that progressive muscle relaxation can reduce the pain of dysmenorrhoea on student A 2012 Faculty of Nursing in Andalas University. This shows that progressive muscle relaxation can reduce the pain of dysmenorrhoea A 2012 School of Nursing student Andalas. It is recommended for young women in order to implement progressive muscle relaxation in overcoming dysmenorrhoea.
\end{abstract}

Key words: Dysmenorrhea, Progressive Muscle Relaxation

\begin{abstract}
Abstrak: Dismenorea merupakan nyeri yang dirasakan ketika mestruasi, terutama terjadi pada perut bagian bawah menyebar sampai pinggang serta paha yang terasa seperti kram. Nyeri yang dirasakan bersifat subjektif. Pada keadaan berat dapat disertai mual dan muntah. 60-70\% penderita dismenorea ini adalah perempuan muda atau remaja, yang mengakibatkan rasa ketidaknyamanan serta berdampak terhadap gangguan aktivitas seharihari, akademis dan sosial. Salah satu terapi non farmakologi yang dapat digunakan untuk mengurangi dismenorea ini adalah relaksasi otot progresif. Penelitian ini bertujuan untuk mengetahui apakah relaksasi otot progresif berpengaruh dalam mengatasi nyeri dismenorea. Subjek penelitian adalah mahasiswi A 2012 di Fakultas Keperawatan UNAND. Jenis penelitian ini menggunakan Quasi-eksperiment tanpa kelompok kontrol dengan pendekatan one group pretest-posttest. Pengambilan sampel menggunakan teknik total sampling dengan 37 orang. Analisa data menggunakan wilcoxon. Hasil penelitian membuktikan adanya pengaruh yang signifikan sebelum dan sesudah diberikan relaksasi otot progresif terhadap nyeri dismenorea pada mahasiswi A 2012 Fakultas Keperawatan UNAND dengan $\mathrm{p}=0,000(\mathrm{p}<0,05)$. Hal ini menunjukan bahwa relaksasi otot progresif dapat menurunkan nyeri dismenorea pada mahasiswi A 2012 Fakultas Keperawatan UNAND. Disarankan untuk remaja putri agar dapat menerapkan relaksasi otot progresif dalam mengatasi dismenorea.
\end{abstract}

Kata kunci: Dismenorea, Relaksasi Otot Progresif.

Masa remaja adalah suatu tahap antara masa kanak-kanak dengan masa dewasa. Masa ini ditandai dengan percepatan perkembangan fisik, mental, emosional dan sosial (Ali \& Asrori, 2010; Dhamayanti, 2009; Proverawati \& Misaroh, 2009). Remaja ini berada pada masa transisi dari masa kanak-kanak kemasa dewasa, dimana dikenal dengan istilah masa pubertas (August, 2009). Hurlock (2004) menyatakan bahwa kriteria yang paling sering digunakan untuk menentukan masa pubertas adalah munculnya menstruasi pertama (menarche) pada wanita dan mimpi basah pada laki-laki.

Menstruasi adalah perdarahan secara periodik dan siklik dari uterus, disertai 
pelepasan (deskuamasi) endometrium (Proverawati \& Misaroh, 2009). Sedangkan Bobak (2004) menyatakan bahwa menstruasi adalah perdarahan periodik pada uterus yang dimulai sekitar 14 hari setelah ovulasi. Panjang siklus menstruasi rata-rata $28+3$ hari dan durasi rata-rata hari menstruasi $5+$ 2 hari dengan total kehilangan darah kurang lebih $130 \mathrm{ml}$. Menstruasi yang terjadi pada remaja merupakan suatu hal yang normal. Namun ada diantara remaja yang mengalami permasalahan pada saat menstruasi. Berbagai masalah yang timbul pada menstruasi merupakan masalah ginekologi yang sering dikeluhkan pada remaja, seperti ketidakteraturan menstruasi, menoragia, dismenorea (nyeri menstruasi), dan gejala lain yang berhubungan. Kejadian yang terbanyak dikeluhkan pada remaja yaitu dismenorea. Sekitar 70\% sampai 90\% kasus dismenorea terjadi saat usia remaja (Proctor dan Farquar, 2002; Singh dkk, 2008).

Dismenorea adalah nyeri selama menstruasi yang disebabkan oleh kejang otot uterus (Price, 2001). Terjadinya nyeri pada saat mentruasi adalah hal yang normal, namun dapat berlebihan apabila dipengaruhi oleh faktor fisik dan psikis seperti stress, serta pengaruh dari hormon prostaglandin dan progesteron (Robert \& David, 2004). Pada saat stress tubuh akan memproduksi hormon adrenalin, estrogen, progesteron serta prostaglandin yang berlebihan. Estrogen dapat menyebabkan peningkatan kontraksi uterus secara berlebihan, sedangkan progesteron bersifat menghambat kontraksi. Peningkatan kontraksi secara berlebihan ini menyebabkan rasa nyeri. Selain itu hormon adrenalin juga meningkat sehingga menyebabkan otot tubuh tegang termasuk otot rahim dan dapat menjadikan nyeri ketika haid (Handrawan, 2008).

Dismenorea primer didefinisikan sebagai nyeri kram yang berulang yang terjadi saat menstruasi tanpa ada kelainan patologik pada pelvis (Dawood, 2006). Penyebab dari dismenorea primer ini yaitu faktor endokrin yang ditandai dengan rendahnya kadar progesteron pada akhir fase corpus luteum, kelainan organik (kelainan letak arah anatomis rahim, perkembangan rahim yang tidak lengkap dan polip endometrium), faktor kejiwaan, faktor konstitusi (anemia), dan faktor alergi. Dismenorea primer banyak dialami pada wanita yang berumur 15-20 tahun (Novia, 2008). Faktor resiko dismenorea primer yaitu usia saat menstruasi pertama kurang dari 12 tahun, belum pernah melahirkan, merokok, riwayat keluarga positif terkena penyakit, kegemukan dan stress (Medicastore, 2004; Anurogo \& Wulandari, 2011 ).

Di Indonesia kejadian dismenorea primer mencapai 54,89\%, sedangkan dismenorea sekunder sebanyak 45,11\% (Proverawati dan Misaroh, 2009). Hendrik (2006) menjelaskan 60-70\% penderita dismenorea itu adalah perempuan muda atau remaja. Kejadian tersebut dapat menunjukkan bahwa dismenorea primer lebih banyak terjadi pada remaja. Dampak dari dismenorea tersebut yaitu terganggunya aktivitas sehari-hari, akademis, sosial dan olahraga (Antao dkk, 2005).

Secara umum penanganan dismenorea terbagi dalam dua kategori yaitu pendekatan farmakologis dan nonfarmakologis. Secara non farmakologik antara lain kompres hangat atau mandi air hangat, tidur yang cukup, hipnoterapi, distraksi, dan teknik relaksasi (Potter \& Perry, 2005). Teknik relaksasi merupakan upaya relaksasi yang dilakukan secara mandiri untuk menurunkan intensitas nyeri, meningkatkan ventilasi paru dan meningkatkan oksigenasi darah. Beberapa penelitian menunjukkan bahwa relaksasi efektif dalam meredakan nyeri (Smeltzer, 2002). Salah satu relaksasi yang dapat kita lakukan untuk mengurangi nyeri yaitu progressive muscle relaxation atau relaksasi otot progressive. Relaksasi otot progresif adalah terapi relaksasi dengan gerakan mengencangkan dan melemaskan otot - otot pada satu waktu untuk memberikan perasaan relaksasi secara fisik. Gerakan mengencangkan dan melemaskan secara 
progresif kelompok otot ini dilakukan secara berturut-turut (Synder \& Lindquist, 2002). Jacobson (1938, dalam Synder \& Lindquist, 2002) menyatakan bahwa tujuan dari relaksasi otot progresif adalah untuk mengurangi konsumsi oksigen tubuh, laju metabolisme tubuh, laju pernafasan, ketegangan otot, kontraksi ventikuler premature dan tekanan darah sistolik serta gelombang alpha otak.

Hasil survey yang dilakukan peneliti pada bulan Februari 2013 terhadap 15 mahasiswi A2012 Fakultas Keperawatan Unand didapatkan jumlah mahasiswi yang mengalami dismenorea setiap bulannya sebanyak 14 orang. Mahasiswi yang mengalami nyeri ringan sebanyak 4 orang $(28,5 \%)$. Mahasiswi ini masih bisa untuk konsentrasi belajar dan beraktivitas. Mahasiswi yang mengalami nyeri sedang sebanyak 7 orang (50\%). Mahasiswi dengan nyeri sedang ini dapat mengabaikan nyeri tersebut walaupun memecah konsentrasi. Mahasiswi dengan nyeri berat sebanyak 3 orang $(21,5 \%)$ yang berakibat sulit beraktivitas dan berkonsentrasi saat belajar. Rata-rata nyeri yang dirasakan mahasiswi selama 1 sampai 3 hari.

Mahasiswi yang menangani dismenorea dengan obat anti nyeri sebanyak $7.2 \%$ dan obat tradisional sebanyak $21,4 \%$. Sebagian mahasiswi mengalami mual setelah meminum obat tersebut. Selain itu, sebanyak 4 orang $(28,5 \%)$ setiap bulannya memilih tidur di mushalla kampus ketika mengalami dismenorea pada saat waktu perkuliahan, dan 2 orang $(14,3 \%)$ diantaranya mengalami mual dan muntah dikampus. Ketika mahasiswi mengalami nyeri yang hebat mereka lebih memilih pulang dan tidak mengikuti perkuliahan. Berdasarkan uraian diatas maka peneliti tertarik untuk meneliti pengaruh relaksasi otot progresif terhadap penurunan dismenorea pada mahasiswi A 2012 keperawatan Unand.

\section{METODE}

1.Jenis penelitian

Penelitian ini menggunakan desain quasieksperiment tanpa kelompok control dengan pendekatan one group pretest-posttest. Rancangan ini tidak ada kelompok pembanding (control) tetapi sudah dilakukan observasi pertama (Pretest) yang memungkinkan peneliti dapat menguji perubahan yang terjadi setelah adanya eksperimen (Setiadi, 2007). Bentuk rancangan ini sebagai berikut:

$$
\begin{array}{lll}
\begin{array}{l}
\text { Pretest } \\
\text { Perlakuan }
\end{array} & \text { post test } \\
\text { O1 } \rightarrow \quad \mathrm{X} & \rightarrow \mathrm{O} 2
\end{array}
$$

Keterangan :
$01=$ Obeservasi skala dismenore sebelum diberikan relaksasi otot progresif

$\mathrm{X}=$ Pemberian relaksasi otot progresif

$02=$ Obeservasi skala dismenore berupa rata-rata setelah diberikan relaksasi otot progresif.

\section{Lokasi Penelitian}

Penelitian ini dilakukan di Fakultas Keperawatan UNAND. Penelitian di mulai dari bulan Januari 2013 sampai Juni 2013.

\section{Populasi dan Sampel Penelitian}

Populasi penelitian adalah keseluruhan objek penelitian atau objek yang diteliti (Notoadmojo, 2005). Populasi penelitian ini adalah seluruh mahasiswi A 2012 Fakultas Keperawatan Unand sebanyak 81 orang. Seluruh populasi dijadikan responden penelitian dengan menggunakan teknik total sampling. Sampel yang didapatkan pada saat penelitian sebanyak 37 orang. Sampel yang digunakan pada penelitian ini dengan kriteria inklusi sebagai berikut: 
1) Bersedia mengikuti Relaksasi otot progresif dari awal penelitian (pre-test) hingga post test dilakukan

2) Berada di tempat pada saat penelitian

3) Responden mengalami dismenorea tipe primer

4) Responden mengalami dismenorea sedang dan berat

5) Responden tidak mengkonsumsi obat anti nyeri

6) Usia 18-20 tahun

\section{Variabel Penelitian}

a.Variabel dependen adalah dismenorea yaitu nyeri akibat kejang otot uterus yang dirasakan mahasiswi pada perut bagian bawah, daerah pantat dan sisi medial paha yang mengakibatkan terpengaruhnya aktivitas sehari-hari. Alat ukur yang digunakan yaitu Mankoski Pain Scale dengan skala rasio yang hasilnya berupa skore $0-10$.

b.Variabel independen adalah relaksasi otot progresif

yaitu suatu teknik relaksasi yang diberikan kepada mahasiswi A 2012 Keperawatan Unand untuk meredakan nyeri dismenorea dengan cara mengencangkan dan melemaskan otot pada satu waktu dari kepala hingga kaki secara berturut-turut untuk memberikan perasaan relaksasi secara fisik.

1. Metode Pengumpulan Data

a. Tahap Pertama

Adalah Pengumpulan data dasar unutk mengumpulkan responden yang memenuhi kriteria sejumlah 37 orang.

\section{HASIL DAN PEMBAHASAN}

Hasil pengambilan data pada mahasiswi A 2012 Fakultas Keperawatan UNAND pada tanggal 8 April 2013 sampai 11 mei 2013 dengan jumlah responden pada saat pre test sebanyak 39 orang. Kemudian di ekslusi 2 orang karena responden tidak bisa menahan nyeri tanpa obat sehingga b. Tahap Kedua

Pengumpulan data variabel bebas, meliputi identitas responden, relaksasi otot progresif yang merupakan bentuk intervensi.

c. Tahap Ketiga

Adalah pengukuran nyeri dismenore yang diperoleh dengan menggunakan skala nyeri Mankonski Pain Scale. Skala nyeri ini dapat membuat mahasiswi lebih mudah untuk menggambarkan derajat nyeri karena dijelaskan setiap karakteristik nyeri pada masing-masing skala nyeri yang dirasakan (France, 2007). Mankonski Pain Scale membagi 4 klasifikasi tingkat skala nyeri yaitu:

1) Tidak nyeri :0

2) Nyeri ringan :1-2

3) Nyeri sedang : $3-6$

4) Nyeri berat :7-10

2. Metode pengolahan dan analisa data

Data diperoleh dengan cara memilih partisipan dalam penelitian sesuai tujuan penelitian kemudian mengukur tingkat nyeri dismenorea sebelum dilakukan tindakan relaksasi otot progresif. Mengajarkan tehnik relaksasi otot progresif, melakukan tindakan mengatasi nyeri dismenorea dengan terapi relaksasi otot progresif dan mengukur tingkat nyeri dismenorea setelah dilakukan tindakan. Data hasil kusioner dan observasi diperiksa dan kemudian diolah menggunakan bantuan program komputer. Analisis data digunakan analisis univariat dan

bivariat. responden pada penelitian ini menjadi 37 orang.

\section{Karakteristik Responden}

Dari 37 orang responden di dapatkan hasil bahwa responden berada pada masa remaja akhir yaitu usia 18 tahun 
sebanyak 24 orang $(64,9 \%)$ dan usia 19 tahun sebanyak 13 orang $(35,1 \%)$. Responden ini sebagian besar bertempat tinggal di kost sebanyak 29 orang a. Analisa Univariat

1. Gambaran Nyeri Dismenorea Sebelum dan Sesudah Diberikan Relaksasi Otot Progresif Pada Mahasiswi A 2012 Fakultas Keperawatan UNAND Tahun 2013.

\begin{tabular}{|c|c|c|c|c|}
\hline \multirow{2}{*}{ NO } & \multirow{2}{*}{ Nama } & \multicolumn{2}{|c|}{ Skala nyeri } & \multirow{2}{*}{ Penurunan } \\
\hline & & Sebelum & Sesudah & \\
\hline 1 & $\mathrm{LT}$ & 7 & 4 & 3 \\
\hline 2 & WY & 6 & 2 & 4 \\
\hline 3 & $\mathrm{MF}$ & 4 & 2 & 2 \\
\hline 4 & FR & 8 & 5 & 3 \\
\hline 5 & $\mathrm{KL}$ & 6 & 2 & 4 \\
\hline 6 & DP & 5 & 2 & 3 \\
\hline 7 & AT & 3 & 1 & 2 \\
\hline 8 & LA & 4 & 1 & 3 \\
\hline 9 & ED & 4 & 2 & 2 \\
\hline 10 & IS & 4 & 1 & 3 \\
\hline 11 & $\mathrm{AF}$ & 9 & 6 & 3 \\
\hline 12 & $\mathrm{RS}$ & 7 & 6 & 1 \\
\hline 13 & MS & 9 & 5 & 4 \\
\hline 14 & WF & 7 & 6 & 1 \\
\hline 15 & WS & 7 & 4 & 3 \\
\hline 16 & AS & 8 & 5 & 3 \\
\hline 17 & $\mathrm{MZ}$ & 9 & 6 & 3 \\
\hline 18 & SP & 3 & 1 & 2 \\
\hline 19 & $\mathrm{FN}$ & 4 & 2 & 2 \\
\hline 20 & $\mathrm{YH}$ & 3 & 2 & 1 \\
\hline 21 & $\mathrm{AO}$ & 4 & 1 & 3 \\
\hline 22 & NS & 3 & 2 & 1 \\
\hline 23 & $\mathrm{ZY}$ & 4 & 2 & 2 \\
\hline 24 & AY & 3 & 1 & 2 \\
\hline 25 & $\mathrm{HE}$ & 3 & 1 & 2 \\
\hline 26 & YN & 3 & 2 & 1 \\
\hline 27 & VR & 3 & 1 & 2 \\
\hline 28 & FA & 4 & 1 & 3 \\
\hline 29 & NP & 3 & 2 & 1 \\
\hline 30 & $\mathrm{KH}$ & 3 & 1 & 2 \\
\hline 31 & $\mathrm{YF}$ & 4 & 2 & 2 \\
\hline 32 & $\mathrm{FH}$ & 3 & 1 & 2 \\
\hline 33 & YR & 5 & 2 & 3 \\
\hline 34 & RN & 4 & 1 & 3 \\
\hline 35 & AA & 4 & 2 & 2 \\
\hline
\end{tabular}

$(78,4 \%)$, selebihnya tinggal bersama orang tua sebanyak 7 orang $(18,9 \%)$ dan asrama 1 orang $(2,7 \%)$. 


\begin{tabular}{|c|c|c|c|c|}
36 & EF & 5 & 2 & 3 \\
\hline 37 & MH & 3 & 1 & 2 \\
\hline MIN & 3 & 1 & 1 \\
\hline MAX & 9 & 6 & 4 \\
\hline MEAN & 4,81 & 2,43 & 2,378 \\
\hline Std Deviasi & 1,984 & 1,708 & 0,861 \\
\hline
\end{tabular}

Dari tabel 5.1 menunjukkan bahwa semua $100 \%$ responden mengalami penurunan nyeri dismenorea setelah diberikan relaksasi otot progresif. Sebanyak 3 orang $(8 \%)$ responden mengalami penurunan nyeri dismenorea tertinggi sebesar 4 skala dan 6 orang $(16 \%)$ responden mengalami penurunan nyeri dismenorea terendah sebesar 1 skala.

b. Analisa Bivariat

2. Distribusi Rata-rata Tingkat Nyeri Dismenorea Pre Test dan Post test Pada Mahasiswi A 2012 Fakultas Keperawatan UNAND Tahun 2013.

\begin{tabular}{|c|c|c|c|c|c|c|}
\hline & $\mathrm{N}$ & Mean & Median & $\begin{array}{c}\text { Standar } \\
\text { deviasi }\end{array}$ & $\begin{array}{c}\text { Mean } \\
\text { penurunan }\end{array}$ & p value \\
\hline Pre test & 37 & 4,81 & 4 & 1,984 & 2,378 & 0 \\
\cline { 1 - 5 } Post test & 37 & 2,43 & 2 & 1,7008 & & \\
\hline
\end{tabular}

Dari tabel 5.2 menunjukkan bahwa rata-rata nyeri dismenorea sebelum diberikan relaksasi otot progresif sebesar 4,81 dan nyeri dismenorea setelah diberikan relaksasi otot progresif sebesar 2,43 , dengan rata-rata penurunan skala nyeri dismenorea setelah diberikan relaksasi otot progresif sebesar

A. Dismenorea sebelum diberikan relaksasi otot progresif pada mahasiswi A 2012 Fakultas Keperawatan UNAND.

Berdasarkan hasil penelitian dapat diketahui bahwa mahasiswi A 2012 sebagian besar mengalami dismenorea sedang 28 orang $(75,7 \%)$ diperoleh bahwa rata-rata skala nyeri dismenorea sebelum diberikan relaksasi otot progresif adalah 4,81. Hal ini sesuai dengan penelitian yang dilakukan oleh Ernawati (2010) tentang terapi relaksasi terhadap nyeri dismenorea pada mahasiswi A 2012
2,378. Berdasarkan hasil uji wilcoxon diperoleh nilai $\mathrm{p}=0,000$ $(\mathrm{p}<0,05)$ yang berarti bahwa terdapat penurunan nyeri dismenorea antara sebelum dan sesudah diberikan relaksasi otot progresif pada mahasiswi A 2012 Fakultas Keperawatan UNAND.

Fakultas Keperawatan UNAND dimana lebih dari separuh mahasiswi mengalami nyeri sedang 31 orang $(62,0 \%)$ dan didukung pula oleh penelitian yang dilakukan Suparto (2011) yang menemukan lebih dari separuh 53\% mahasiswi mengalami dismenorea sedang.

Dismenorea sedang yang dirasakan mahasiswi merupakan nyeri dismenorea primer yang merupakan nyeri kram tanpa ada kelainan patologik pada pelvis (Dawood, 2006). Dita (2009) menyatakan bahwa dismenorea primer biasanya dimulai pada saat wanita berumur 2 sampai 3 tahun setelah manarche dan 
mencapai puncaknya pada usia 15 sampai 20 tahun. Begitu juga dengan teori Basalamah et .al (1993) dalam Yustianingsih (2004), bahwa dismenorea primer dapat dijumpai pada wanita muda yang telah berusia 15 sampai 20 tahun dan akan menghilang pada usia diatas 25 tahun tanpa ditemukan kelainan alat genital pada pemeriksaan ginekologi. Hal ini sesuai dengan karakteristik responden bahwa sebagian besar mahasiswi (64,9\%) berumur 18 tahun. Ini didukung pula dengan pernyataan Wahit et al (2007) bahwa faktor umur adalah variabel penting yang mempengaruhi respon nyeri.

Selain umur, dukungan keluarga juga mempengaruhi nyeri. Ini dijelaskan oleh Smeltzer \& Bare (2002) bahwa faktorfaktor yang mempengaruhi nyeri individu diantaranya adalah perhatian dan support keluarga. Mahasiswi yang mengalami nyeri seringkali bergantung pada anggota keluarga untuk memperoleh dukungan, perlindungan, dan bantuan. Namun, bedasarkan karakteristik responden mahasiswi sebagian besar $(78,4 \%)$ bertempat tinggal di kost sehingga kurang mendapatkan dukungan dari keluarga ketika mengalami dismenorea.

Namun, pada penelitian ini ditemukan responden dengan dismenorea berat sebanyak 9 orang (24,3\%). Didukung dengan penelitian Fajaryati (2011) bahwa $(26,2 \%)$ mahasiswi mengalami dismenorea berat. Hal ini dikarenakan beberapa faktor diantaranya stres dan ansietas.

Responden merupakan mahasiswi tahun pertama. Sehingga memungkinkan terjadinya ansietas dan stress. Hal ini sesuai dengan penelitian yang dilakukan Hermawati (2005) bahwa mahasiswa baru cenderung mengalami stres yang tinggi disebabkan oleh beberapa faktor seperti belum pernah mengalami kost sebelumnya, kesulitan beradaptasi dengan lingkungan, masalah pribadi, kesulitan berteman, memahami materi kuliah, masalah kesehatan, homesick, dan masalah keuangan. Stres yang dialami akan mempengaruhi sistem menstruasi yang berdampak nyeri ketika mengalami menstruasi.

B. Dismenorea setelah diberikan relaksasi otot progresif pada mahasiswi A 2012 Fakultas Keperawatan UNAND tahun 2013.

Tingkat nyeri setelah diberikan relaksasi otot progresif sebagian besar berada pada tingkat nyeri ringan sebanyak 28 orang $(75,7 \%)$ dan selebihnya mengalami nyeri sedang sebanyak 9 orang $(24,3 \%)$. Rata-rata skala nyeri dismenorea yang diperoleh setelah diberikan relaksasi otot progresif ini adalah 2,43. Responden yang mengalami nyeri ringan ini berawal dari nyeri sedang yang kemudian mengalami penurunan tingkat nyeri setelah di berikan relaksasi otot progresif. Begitu juga pada nyeri berat menjadi nyeri sedang.

Penurunan tingkat nyeri ini dikarenakan oleh adanya relaksasi yang dapat menurunkan intensitas nyeri, meningkatkan ventilasi paru dan meningkatkan oksigenasi darah serta merangsang sekresi endorphin (Smeltzer, 2002). Endorphin yang disekresikan ini berhubungan dengan teori "gate control" dari Melzack dan Wall (1965). Teori ini mengatakan bahwa impuls nyeri dihantarkan saat sebuah pertahanan dibuka dan impuls dihambat saat sebuah pertahanan ditutup. Salah satu cara menutup mekanisme pertahanan ini adalah dengan merangsang sekresi endorphin (penghilang nyeri alami) yang akan menghambat pelepasan substansi $P$ (Proverawati \& Misaroh, 2009). Hal ini sesuai dengan penelitian yang dilakukan oleh Setyawanti (2011), dimana disimpulkan bahwa relaksasi otot progresif dapat mempengaruhi untuk mengurangi nyeri haid dan tanda-tanda vital.

Sebuah studi eksperimen yang dilakukan oleh Praseetha (2012) di Brasil didapatkan hasil bahwa relaksasi otot 
progresif dapat mengurangi persepsi nyeri pada 61 responden. Nyeri yang dirasakan mengalami penurunan satu tingkat dari berat menjadi sedang dan sedang menjadi ringan setelah diberikan relaksasi otot progresif. Hasil ini menyatakan bahwa relaksasi otot progresif memiliki nilai yang signifikan untuk penurunan dismenorea.

C. Pengaruh relaksasi otot progresif terhadap penurunan dismenorea pada mahasiswi A 2012 Fakultas Keperawatan UNAND tahun 2013.

Hasil penelitian yang dilakukan pada mahasiswi A 2012 Fakultas Keperawatan UNAND tahun 2013, setelah dilakukan uji statistik didapatkan nilai $\mathrm{p}=$ $0,000(\mathrm{p}<0,05)$, maka dapat disimpulkan bahwa terdapat perbedaan yang signifikan tingkat nyeri sebelum dan sesudah diberikan relaksasi otot progresif. Dimana sebelum diberikan relaksasi otot progresif terdapat 9 orang $(24,3 \%)$ yang mengalami nyeri berat dan setelah diberikan relaksasi otot progresif 9 orang $(24,3 \%)$ menjadi nyeri sedang, begitu juga dengan 28 orang $(75,7 \%)$ yang mengalami nyeri sedang terjadi penurunan satu tingkatan nyeri menjadi nyeri ringan. Rata - rata penurunan skala nyeri dismenorea setelah relaksasi otot progresif adalah 2,378

Hal ini sesuai dengan penelitian Kamali (2002) di Iran. Pada penelitian ini dilakukan pada 88 mahasiswi yang tinggal di asrama. Mahasiswi ini dibagi atas dua kelompok yaitu kelompok eksperimen (44orang) dan kelompok kontrol (44 orang). Hasil penelitian pada kelompok eksperimen didapatkan sebanyak 40 orang mengalami penurunan derajat nyeri yang dirasakan ketika dismenorea. Peneliti menyimpulkan bahwa teknik relaksasi otot progresif efektif dalam mengurangi nyeri dismenorea.

Dismenorea yang dirasakan oleh responden merupakan akibat di sekresinya estrogen dan penurunan progesteron. Penurunan progesteron mengakibatkan terbentuknya prostaglandin dalam jumlah yang besar sehingga arteri spiral menjadi spasme dan terjadi kontraksi myometrium Akibatnya uterie menjadi ischemia yang akhirnya terasa nyeri. Pada saat melakukan relaksasi otot progresif maka otot yang mengalami spasme/ketegangan menyebabkan vasodilatasi pembuluh darah di bagian abdomen sehingga sirkulasi dalam darah menjadi lancar, mencegah terjadinya ischemia dan mencegah produksi zat-zat kimia yang akan merangsang nyeri (Benson \& Proctor, 2000).

Selain itu gerakan relaksasi otot progresif dapat menstimulasi pengeluaran hormon endorphin yang memberikan kenyamanan pada tubuh. Hormon ini dapat berfungsi sebagai obat penenang alami yang diproduksi di otak dan susunan syaraf tulang belakang. Endorphin bekerja dengan mengikat reseptor opiat yang ada pada sistem limbik, otak tengah, medulla spinalis dan usus. Reseptor opiat dan opiat endogen ini kemudian membentuk suatu sistem penekanan nyeri intrinsik. Ikatan antara opiat dengan reseptor inilah yang akan dapat mengurangi nyeri dengan mencegah dibebaskannya sebagai neirotransmiter penghasil nyeri (Price \& Wilson, 2006). Oleh sebab itu relaksasi otot progresif sangat tepat digunakan ketika mengalami nyeri menstruasi (dismenorea) dan perlu dilakukan secara mendalam agar penurunan nyeri dapat dirasakan secara spesifik.

\section{KESIMPULAN DAN SARAN}

Pada penelitian ini dapat disimpulkan bahwa adanya pengaruh relaksasi otot progresif yang signifikan terhadap penurunan dismenorea pada mahasiswi A 2012 Fakultas Keperawatan UNAND dengan $p=0,000(p<0,05)$

Saran dari peneliti ini adalah

1. Bagi responden

Agar dapat memanfaatkan relaksasi otot progresif untuk mengurangi nyeri 
menstruasi sebagai salah satu cara yang aman dan mudah untuk dilakukan di rumah. Responden juga dapat mendukung serta memfasilitasi teman dan anggota keluarga dalam melaksanakan relaksasi otot progresif untuk mengurangi dismenorea.

2. Bagi institusi pendidikan

Agar dapat memberikan informasi kepada mahasiswi tentang pemanfaatan relaksasi sebagai salah satu pengobatan secara nonfarmakologi dalam menurunkan nyeri menstruasi (dismenorea).

3. Bagi penelitian selanjutnya

Disarankan untuk bisa mencobakan relaksasi otot progresif kepada seluruh kategori nyeri dismenorea dengan frekuensi yang lebih banyak dan teratur.

\section{DAFTAR PUSTAKA}

Anurogo \& Wulandari.(2011).Cara jitu mengatasi nyeri haid. Yogyakarta: C.V Andi

Bobak, I. M., Jensen, M. D., \& Lowdermilk, D. L. (2004). Buku ajar keperawatan maternitas (Alih bahasa: Maria A. Wijayarini \& Peter I. Anugerah) (Edisi 4). Jakarta: EGC.

Candra. (2012). Nyeri perut kala menstruasi. Diakses pada tanggal 24 Februari 2013 dari http://www.republika.co.id

Cunningham, F.G., Gant, N., Leveno, K. J., Haunt, L. C., \& Wenstrom, K. D. (2005). William obstetrics (Alih bahasa: A. Hartono, J. Suyono, \& Brahm U. Pendit ). Jakarta: Buku Kedokteran EGC.

Dawood, MY and Khan-Dawood, Firyal S. 2007. Clinical efficacy and differential inhibition of menstrual fluid prostaglandin $\mathrm{F} 2 \alpha$ in a randomized, doubleblind, crossover treatment with plasebo, acetaminophen, and ibuprofen in primary dysmenorrhea. American Journal of Obstetrics \& Gynecology Volume 196, Issue 1 , Pages 35.e1-35.e5.

Hendrik, H. (2006). Problema haid: Tinjauan syariat islam dan medis. Jakarta: Tiga Serangkai.

Jacobson, E. (1974). Progressive relaxation : A physiological and clinical investigation of muscular states and their significance in psychogy and medical practice. Chicago, IL : The University of Chicago Press.

Nursalam. (2009). Konsep dan penerapan metodologi penelitian ilmu keperawatan-pedoman skripsi, tesis, dan instrument penelitian keperawatan (Edisi 2). Jakarta: Salemba Medika.

Price, S. A., \& Wilson, L. M. (2005). Patofisiologi konsep klinis prosesproses penyakit (Alih bahasa: A. Dharma) (Edisi 6). Jakarta: EGC

Proctor, M., Latthe, P., Farquhar, C., Khan, K., Johnson, N. 2005. Surgical interruption of pelvic nerve pathways for primary and secondary dysmenorrhoea (Cochrane Review). In: The Cochrane Library, Issue 4.

Proverawati, A., \& Misaroh, S. (2009). "Menarche: Menstruasi pertama penuh makna. Yogyakarta: Nuha Medika.

Smeltzer \& Brenda. 2002. Buku Ajar Keperawatan Medikal Bedah Brunner \& Suddarth vol. 1. Jakarta: EGC.

Snyder, M \& Lindquist, R. 2002. Complementary Alternative Therapies Nursing 4th ed. New York: Springer Pusblishing Company.

Widyastuti, Y, dkk. (2009).Kesehatan reproduksi.Yogyakarta: Fitramaya

Wijayarini, M.A (2004). Buku ajar keperawatan maternitas. Jakarta : EGC. 